\title{
A univocidade do sinal e a polissemia do símbolo
}

\author{
The univocity of the sign and the polysemy of the symbol
}

José Wilson Vasconcelos Jr.

Psicólogo, mestre em Filosofia pela Universidade Federal do Ceará (UFC), professor do Departamento de Psicologia da mesma instituição (UFC), Fortaleza, CE - Brasil, e-mail: vasconcelos.wilson@gmail.com

Recebido: $16 / 05 / 2012$ Received: 05/16/2012

Aprovado: $20 / 11 / 2012$ Approved: $11 / 20 / 2012$

\section{Resumo}

Trabalhamos a concepção junguiana de significação, segundo os conceitos de sinal e símbolo. Para tanto, discutimos a distinção que a Psicologia Analítica faz entre duas formas de pensar: o pensar dirigido ou intelecto e o fantasiar ou pensar intuitivo. Mediante as noções de univocidade semiótica e polissemia simbólica explicitamos a conexão entre o pensamento dirigido e a discriminação consciente dos pares opostos, mostrando como o circuito lógico da abstração formal forma-se desde as operações do pensamento dirigido e da constituição dos sinais, cuja significação é unívoca e convencionada, tornando-se independente daqueles contextos ideoafetivos apenas ex nunc e não ab ovo. Do mesmo modo, resta claro que o fantasiar produz os símbolos polissêmicos que aludem constitucionalmente ao inconsciente, donde a ambiguidade e a indeterminação das produções da fantasia. Inquirimos, então, desde tal articulação, qual o papel da ferramenta lógica na confecção do discurso psicológico sobre a polissemia simbólica e desenvolvemos a circunscrição, em Psicologia Analítica, do uso de um estilo discursivo antitético como exigência da própria fenomenologia psíquica às afirmações psicológicas vivas. Consideramos, por fim, que o apego unilateral de nossa presente consciência coletiva às produções significativas semióticas durante a adaptação psíquica expõe-se ao perigo mítico do "olhar para trás" e seu destino petrificante e mortal.

Palavras-chave: Intimidade. Relação terapêutica. Análise do comportamento.

\begin{abstract}
We work on the Jungian conception of meaning, according to the concepts of sign and symbol. For this purpose, we discuss the distinction that Analytical Psychology makes between two forms of thinking: the driven thinking or intellect and the intuitive thinking or fantasizing. Through the notions of semiotic univocity and symbolic polysemy we make explicit the connection between the driven thought and the conscious discrimination of opposing pairs, showing how the logic circuit of formal abstraction is formed from the operations of the driven thought and from the constitution of signs, whose meaning is univocal and conventionalized, becoming independent of those ideo-affective contexts only ex nunc and not ab ovo. Likewise, it is clear that fantasizing produces the polysemic symbols that allude constitutionally to the unconscious, whence the ambiguity and indetermination of the productions of fantasy. We inquire, then, from such articulation, what is the role of the logical tool in the confection of psychological discourse on symbolic polysemy and we develop the circumscription, in Analytical Psychology, of the use of an antithetical discursive style as a requirement of psychic phenomenology itself to
\end{abstract}


living psychological claims. We consider, lastly, that the unilateral attachment of our present collective consciousness to significant semiotic productions during psychic adaptation exposes itself to the mythical danger of "looking back" and its petrifying and mortal destination.

Keywords: Symbol. Sign. Fantasy. Intellect. Logic.

\section{Introducão}

Jung $(1989, \S 11)^{1}$ denominou lógico o pensamento dirigido, expondo, desse modo, sua conexão com o proprium da consciência: a discriminação de opostos ${ }^{2}$. A discriminação se faz de forma lógica, assumindo como válida a inexistência de um terceiro fator entre eles. A conexão pensamento dirigido>lógica>discriminação coordena-se com a ideia comumente aceita em Psicopatologia de que o "pensamento normal" caracteriza-se por ser "regido pela lógica formal e orientar-se segundo a realidade e os princípios de racionalidade da cultura na qual o indivíduo se insere" (Dalgalarrondo, 2008, p. 196). Conhecemos ao diferenciar. Distinguimos, por exemplo, o sujeito do objeto, o Eu do não Eu, o macho da fêmea, o alto do baixo, o quente do frio etc. A discriminação dos opostos é, de acordo com Jung (2000a, §419), válida apenas para a consciência e "corresponde a uma condição necessária do pensar".

A lógica diz tertium non datur, significando que somos incapazes de imaginar os opostos em sua unicidade. Em outras palavras, a abolição de uma antinomia existente apesar de tudo, só pode valer como postulado. As coisas porém não são assim para o inconsciente, cujos conteúdos são paradoxais e antinômicos por si mesmos, inclusive a categoria do ser (Jung, 2000a, §419).
A consciência persegue "o sentido unívoco e as decisões claras" (Jung, 1985, p. XV) mediante a discriminação; seu esforço de significação exclui (ou busca excluir) os sentidos múltiplos, o ambíguo e o incompatível com a ideia diretora. Essa lapidação semântica elabora o sinal, cujo intuito é significar de modo determinado e designar convencionalmente alguma coisa conhecida, pelo que se distingue do símbolo (Jung, 1989, 1991). 0 pensamento fantástico, entretanto, traspassa com sua multiformidade a consciência e a cultura, desenvolvendo-se autonomamente nos sonhos, nos mitos e nos ideários, permanecendo função indelével da alma humana. A fantasia vislumbrou imagens de "ilógicos" hermafroditas, como a Rebis alquímica ${ }^{3}$ ou Oxalá, supremo Orixá na religião iorubana' também as "absurdas" mães virgens como a Atená grega, a Maria cristã ou as cis de nossos indígenas de língua Tupi ${ }^{4}$.

Ao discutir as relações entre discriminação de opostos (condição do pensar dirigido) e fantasia, sinal e símbolo, pretendemos melhor articular a concepção junguiana de significação, a qual descobre no conteúdo da fantasia a matéria-prima simbólica das construções semióticas do pensamento lógico dirigido.

1 Para a Obra Completa de Jung, substituiremos a indicação da página (p.) pelo parágrafo (§).

2 "A separação dos pares opostos deve-se totalmente à diferenciação consciente, pois só a consciência pode reconhecer o conveniente e distingui-lo do inconveniente ou inútil" (Jung, 1991, §§ 170, 774).

3 Sobre as figuras paradoxais da alquimia cf. Jung (1985).

4 "O indígena não concebe nada do que existe sem mãe. Simplista, estende a necessidade de uma mãe, que ele teve para existir, a tudo o que existe; o pai, desde que ele acredita nas virgens parideiras, não é de necessidade absoluta. A mãe, pois, é sempre necessária para que haja vida" (Cascudo, 1954, p. 282). 


\section{Intelecto e fantasia}

C. G. Jung distinguiu em Símbolos da Transformação duas espécies do pensar (Jung, 1989): o pensamento dirigido (ou intelecto) e o fantasiar (ou pensamento intuitivo ${ }^{5}$ ). 0 primeiro trabalha subordinando a cadeia associativa a uma ideia superior e, quando intenso, realiza-se como linguagem; dirige-se para fora, como se o sujeito quisesse comunicá-lo, ensiná-lo ou convencer alguém; é cansativo, pois requer o empenho continuado da atenção. Primitiva e espontânea, a segunda forma do pensar age sem esforço, com conteúdos encontrados prontos na diversidade mnêmica; se é dirigida, o é por temas inconscientes. Nela decresce o pensamento por palavras enquanto majora um jogo de imagens ${ }^{6}$ que a função do real ${ }^{7}$ estima incongruente; a fantasia manifesta disposição de espírito criativa e livre, apresentando as coisas segundo as aspirações íntimas.

0 pensar dirigido é "um pensamento que se adapta à realidade" (Jung, 1989, §11), que examina a sucessão e a simultaneidade dos objetos e estabelece uma ordem entre as imagens mentais; consiste numa assimilação psíquica do meio ambiente, com o consequente esgotamento vital. 0 fantasiar, de outra maneira, afasta-se da realidade concreta exterior - alheia-se - liberando tendências subjetivas latentes e aparentemente estéreis na adaptação ao meio. Convém ressaltar logo que, de acordo com Jung (1989, §20, n. 22):

É bem verdade que o fantasiar de início e imediatamente é "improdutivo", isto é, inadequado e por isso inútil sob o ponto de vista da aplicação prática. Mas, a longo prazo, justamente a fantasia despreocupada revela forças e conteúdos criativos, exatamente como os sonhos. Tais conteúdos, via de regra, nem podem ser reconhecidos de outra forma, a não ser justamente através do pensamento passivo, associativo, fantástico (grifos nossos).

Ectopsíquico, gregário e adaptativo, o cerne do pensamento dirigido está na ligação rigorosa e

5 Em Tipos Psicológicos (1991), Jung refinou sua distinção de 1912 - primeira redação de Símbolos da Transformação, com o título de Metamorfoses e Símbolos da Libido - apondo diferença entre pensamento ativo e passivo. "O pensamento ativo é um agir da vontade, o passivo é um acontecer"; afirmando, em seguida, que "O pensamento ativo corresponderia, então, a meu conceito de pensamento dirigido. O pensamento passivo foi insuficientemente classificado como 'fantasiar' em meu trabalho acima citado. Hoje o chamaria de pensamento intuitivo" (Jung, 1991, §873); no mesmo lugar, ainda, denominou de intelecto o primeiro e de intuição intelectual o segundo (§875). Pieri (2002, p. 371) considerou que Jung, nessa passagem, substituiu “definitivamente" a expressão pensar fantástico ou fantasiar pela expressão pensamento intuitivo. Apesar do consistente argumento do autor, devemos nos lembrar que Jung não modificou os termos na edição de 1952 do seu famoso estudo sobre os prelúdios de uma esquizofrenia, no qual, segundo os editores: "Praticamente em todos os parágrafos encontramos modificações, acréscimos ou cortes" (Jung, 1989, p. X). Considerando a revisão exaustiva mediante a qual Jung reescreveu o livro, parece-nos difícil que ele deixasse escapar tema tão importante. Consideramos, quanto a isso, que o elo entre pensar intuitivo e imaginação pede investigação maior.

6 Jung chamou imagem "a todos os conteúdos conscientes", pois uma "entidade psíquica só pode ser um conteúdo da consciência, isto é, só pode ser representada quando é representável, ou seja, precisamente quando possui a qualidade de imagem." (Jung, 1986b, §608). A linguagem, coisa óbvia, também é imagem no conceito e na palavra. A distinção do autor, portanto, não quis indicar ausência de imagem no pensamento dirigido e sua presença no fantasiar, mas a prevalência de outras variedades imagéticas (visuais, acústicas, táteis etc.) no segmento da fantasia.

7 No sentido dado por Pierre Janet (2006, p. 300): “Je crois, pour ma part, qu'il y a une très grande différence dans les opérations psychologiques suivant qu'elles s'exercent sur des objets imaginaires ou abstraits, ou bien qu'elles s'exercent à propos de choses réelles qui existent, aujourd'hui même, devant nous, qu'il s'agit de percevoir, de modifier, ou dont il s'agit de se défendre. Il y a, à mon avis, une fonction du réel qui consiste dans l'appréhension de la réalité par la perception ou par l'action qui modifie considérablement toutes les autres opérations suivant qu'elle doit s'y ajouter ou qu'elle ne s'y ajoute pas."[Creio, de minha parte, que existe uma diferença muito grande nas operações psicológicas conforme elas se exerçam seja sobre objetos imaginários ou abstratos, seja quanto a coisas reais (concretas) que existam, no presente, diante de nós. Estas precisam de ser percebidas, modificadas, mas às vezes, precisamos nos defender delas. Existe, na minha opinião, uma função do real que consiste na apreensão da realidade pela percepção ou pela ação que modifica consideravelmente todas as outras operações conforme ela deva acrescentar-se aí ou não.] (Traduzimos com a colaboração do Prof. Ricardo L. L. Barrocas, pelo que somos gratos). Jung permaneceu mencionando o conceito fonction du réel de Janet em seus escritos, chegando a incorporá-lo ao conceito de função sensação. (Cf. Jung, 1997, §21).

Psicol. Argum. 2013 out./dez., 31(75), 717-727 
hierarquizada das associações e, por isso, o "nosso pensamento dirigido ou lógico a rigor é um pensamento da realidade" (Jung, 1989, §11) (grifos nossos); ele é "o instrumento evidente ${ }^{8}$ da cultura" (Jung, 1989, §17).

\section{Significação: sinal e símbolo}

A Psicologia Analítica discriminou dois conceitos unidos no evento da significação" o símbolo e o sinal. Sobre o assunto, Jung afirmou: "Em minha concepção, o conceito de símbolo é bem distinto do simples conceito de sinal" $(1991, \S 903)^{10}$; e importa enfatizarmos este pormenor, pois nossa tradição intelectual usou sinal e símbolo sobretudo como sinônimos.

Abbagnano (2000, p. 901), por exemplo, apresentou-nos dois significados para símbolo: "1. 0 mesmo que signo", corrente na linguagem comum e "2. Uma espécie particular de signo", cuja concepção específica se altera em diversos pensadores, como Pierce, Dewey e outros que, todavia, concordam com a subsunção mencionada. No verbete signo, outrossim, o termo símbolo comparece subsumido ou equivalendo a signo (Abbagnano, 2000, p. 894-896). Lato sensu, portanto, o signo consiste em qualquer elemento ou evento por meio do qual se faz referência a outro, mas seu uso próprio restringe-se à referência de um objeto ou evento presente a outro objeto ou acontecimento ausente, ou cuja presença ou não presença seja indiferente (Abbagnano, 2000).

A relação entre sinal e símbolo, na Psicologia Analítica, não segue a direção tradicional na linha de subsunção, pois o conceito mais "largo", nela, não é o de sinal, mas sim o de símbolo. 0 sinal possui, para Jung, função restritiva, implicando (ou pretendendo implicar) relação inequívoca de significado entre representante e representado. 0 símbolo amplia, entretanto, o contexto semântico ao conjungir em si inúmeros representantes possíveis com um mesmo e poderoso ponto cego referido. J. Jacobi (1991) afirmou que, apesar das várias acepções e interpretações, o símbolo sempre indicou algo além do sentido superficial e visível, comportando sentido invisível e profundo. Para Jung, portanto:

O símbolo é uma expressão indeterminada, ambígua, que indica alguma coisa dificilmente definível, não reconhecida completamente. 0 "sinal" tem um significado determinado, porque é uma abreviação (convencional) de alguma coisa conhecida ou uma indicação correntemente usada da mesma. Por isso o símbolo possui numerosas variantes análogas, e quanto mais possuir, tanto mais completa e correta é a imagem que traça de seu objeto (Jung, 1989, §180) (grifos nossos).

A função semiótica pode ser formulada assim: $x$ representa ou designa abreviadamente $y$ ou, simplesmente: $x$ significa $y$. 0 signo estabelece significado fixo ou relativamente fixo, tal como, por exemplo, nas siglas, nos emblemas, nos logotipos, nas marcas ou nos chamados "símbolos" matemáticos e lógicos que, psicologicamente, constituem sinais. Os símbolos, em vez disso, surgem como "a melhor formulação possível de algo relativamente desconhecido, não podendo, por isso mesmo, ser mais clara ou característica” (Jung, 1991, §904). O símbolo indica um desconhecido cuja existência, postulada ou conhecida, faz conjeturar significados. Por isso, "um símbolo não define nem explica", ele "aponta para fora de si" (Jung, 1986b, §644), aludindo ao inconsciente.

Em sua prenhez semântica, não reduzido ou explicado arbitrariamente, guardando-se para o

8 O que não significa a inutilidade cultural do pensar intuitivo que, aliás, constitui o elemento criativo inevidente da cultura.

9 Jung usou o parentesco entre Bedeutung (significado ou significação) e Deutung (interpretação) para indicar que o fato puro não cria sentido por si só, pois depende sempre da atividade do psiquismo; deste modo, não existe Bedeutung sem Deutung (cf. Jung, 1979, §431). 0 mesmo uso em texto anterior, porém ainda hesitante e interrogativo, em Jung (1987, §121).

${ }^{10}$ Zeichen e Symbol, são os termos em alemão, no original consta: "Der Begriff eines Symbol ist in meiner Auffassung unterschieden von dem Begriff eines bloßen Zeichens." (Jung, 1950, p. 641-642). A tradução portuguesa para Zeichen dada no Dicionário Junguiano, de Pieri (2002), foi signo e não sinal. 0 mesmo na tradução do Dicionário de Filosofia de Abbagnano (2000).

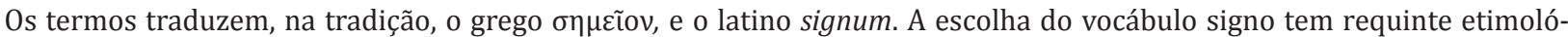
gico, em português, mas o termo Zeichen aparece na composição de termos como Fragezeichen (ponto de interrogação), Ausrufezeichen (ponto de exclamação), Verkehrszeichen (sinal de trânsito), para os quais utilizaríamos o vernáculo sinal (sinais de pontuação, sinais de trânsito). Signo e sinal, portanto, são sinônimos neste trabalho. 
observador como expressão insuperável daquilo apenas pressentido, o símbolo veicula a participação do inconsciente na consciência (Jung, 1991). Constituindo função complexa de abertura para o não Eu, conjura variações de significado e ocasiona verdadeira polissemia ${ }^{11,}$ mediante sua ambiguidade e indeterminação.

Se o símbolo alude ao inconsciente e a cisão fundamental do organismo psíquico, como teoriza a Psicologia Analítica, e ocorre em cada conteúdo anímico de modo que "[...] não há um conteúdo consciente que não seja também inconsciente sob outro aspecto" (Jung, 1986a, §385) ${ }^{12}$, concluímos que todo fenômeno psicológico é ou pode operar como símbolo devido a sua irrecusável participação no inconsciente. Tal concepção depende evidentemente da atitude simbólica da consciência, capaz de considerar "o fato dado não apenas como tal, mas como expressão de algo desconhecido" (Jung, 1991, §907). Uma imagem, por conseguinte, pode ser simbólica para um homem e apenas sinal para outro. Entretanto:

Também é possível o caso inverso. Da mesma forma há produtos cujo caráter simbólico não depende unicamente da atitude da consciência que observa, mas que impõem ao observador seu efeito simbólico. Esses produtos são constituídos de tal forma que lhes faltaria qualquer significado se não recebessem um sentido simbólico. Como fato puro, um triângulo com um olho no centro é tão sem sentido que seria impossível ao observador considerá-lo mera brincadeira. Tal figura evoca de imediato uma concepção simbólica (Jung, 1991, §907).

\section{Sinal, lógica e pensamento dirigido}

Meditando sobre as características do sinal, compreendemos que seu reino por excelência é a Lógica. Especialmente quando essa disciplina passou a trabalhar com linguagens artificiais, buscando estabelecer sentidos inequívocos e, dessa maneira, evitar ambiguidades no segmento das análises formais. A Lógica, entenda-se, não está propriamente empenhada na pesquisa do processo mental do raciocínio:

Não é de interesse da lógica investigar como esse processo ocorre: ainda que a lógica muitas vezes seja caracterizada como a "ciência do raciocínio", ela não se considera, de modo algum, parte da psicologia. A lógica não procura dizer como as pessoas raciocinam [...], mas se interessa primeiramente pela questão de se aquelas coisas que sabemos ou acreditamos - o ponto de partida do processo - de fato constituem uma boa razão para aceitar a conclusão alcançada, isto é, se a conclusão é uma consequência daquilo que sabemos. (Mortari, 2001, p.6).

Preocupada em como a conclusão de um argumento decorre devidamente justificada pela relação das informações disponíveis, a Lógica afasta-se do processo psíquico do raciocínio para concentrar-se na análise formal das proposições, i.e., saber se os argumentos valem ou não. À Lógica interessa a consequência de um argumento e não o seu conteúdo, de maneira que um argumento pode ser considerado válido se sua forma for coerente, ainda que os

\footnotetext{
${ }^{11}$ Jung afirmou muitas vezes a polissemia simbólica. Mostrou, p. ex., o caráter paradoxal do símbolo ("o símbolo significa tanto uma coisa como outra, e por isso é um paradoxo" [1988, §282]), apontou nele "várias camadas de sentido" (1979, §385), sua "multiplicidade de sentido" e "riqueza de referências quase ilimitadas" (2000b, §80).

12 Difícil entender como certos psicólogos junguianos ainda pensam a cisão consciente/inconsciente de maneira concretista e obtusa, apesar de indicações tão precisas de Jung. Imaginam "pacotes" cujos conteúdos permutariam de um para outro, sem inter-relações. Confundem a facilitação das imagens didáticas com a correta formulação teórica da autorregulação entre consciente e inconsciente. De acordo com os antigos, todavia, abusus non tollit usum [0 abuso não impede o uso]. Não precisamos abandonar as metáforas didáticas desde que delas não exageremos, porque as consequências desse abuso não são desprezíveis na conjunção teoria-praxe. Diríamos, cum grano salis, que a cisão sistêmica do organismo psíquico exige pensamento mais "topológico" e menos "geográfico".
} 
objetos referidos não existam; as questões de fato não importam ${ }^{13}$ (Mortari, 2001).

Para a Lógica, portanto, argumento válido (formalmente consequente) e correto (factualmente verdadeiro) são coisas diferentes. "Determinar, para cada argumento, se suas premissas são verdadeiras ou não, não é uma questão de lógica. Caso contrário a lógica teria de ser a totalidade do conhecimento humano. [...] Mas a lógica não pretende ser a ciência de tudo" (Mortari, 2001, p. 22).

Justamente por se definir como ciência formal, a Lógica recorreu à criação de linguagens artificiais, salvaguardando-se do embaraço semântico constante numa língua natural. Um desses empecilhos, p. ex., é a evolução dos idiomas, que mudam sintática e semanticamente. Em tempo, "uma linguagem artificial tem uma gramática rigorosamente definida, que não se altera com o tempo" (Mortari, 2001, p. 33). As palavras de uma língua viva estão sujeitas a múltiplas significações e ambiguidades ${ }^{14}$. Para a Lógica, "fica mais fácil trabalhar com linguagens artificiais - nas quais as palavras são substituídas por símbolos" (Mortari, 2001, p. 33) e as dificuldades semânticas da língua natural, eliminadas. 0 que a Lógica chama de símbolos da linguagem artificial, a Psicologia Analítica denomina sinais. Essa depuração das dificuldades do idioma só ocorre mediante uma determinação convencional dos significados de termos básicos.

Vejamos, e.g., a linguagem do Cálculo Quantificacional Clássico (CQC). Nela, as letras de $a, \ldots . t$ (minúsculas) representam constantes individuais; designam indivíduos específicos e eles somente. Da mesma forma, de $u, \ldots z$, temos variáveis individuais designando indivíduos não especificados. As letras maiúsculas, por outro lado, representam sempre uma propriedade e são chamadas de constantes de predicado. E, dessa maneira, seguem as demais convenções. Sempre encontramos uma relação semiótica de forma $\mathrm{x}$ significa $\mathrm{y}^{15}$; algo ainda mais evidente no caso dos operadores e quantificadores, os chamados "símbolos lógicos" de "significado fixo", que são: os operadores de $\urcorner$ (negação), Ú (disjunção), Ù (conjunção), $\rightarrow$ (implicação), $\leftrightarrow$ (bi-implicação); e os quantificadores " (universal) e \$ (existencial) (Mortari, 2001). A Lógica, consequentemente, arrima-se na univocidade dos sinais elaborados em seu esforço de formalização.

Constituindo-se lógico o pensamento dirigido, compreendemos a dignidade e a importância alcançadas pela Lógica em nossa tradição intelectual que, como disciplina, recua até Aristóteles (384-322 a.C.). Trata-se de sofisticação cultural encontrada pari passu com o desenvolvimento da nossa consciência coletiva ocidental. Interessa averiguar até que ponto, na feitura de um discurso sobre o simbólico, cabe o uso semiótico e, inversamente, se tal discussão não violenta a Lógica.

Tomamos por hipótese que a Lógica se constituiu pela abstração dos circuitos operatórios do pensamento dirigido. Abstração, aqui, na definição precisa dada por Jung em Tipos Psicológicos:

É extrair e isolar um conteúdo (um significado, uma característica geral etc.) de um contexto, formado por outros elementos, cuja combinação em um todo constitui algo único ou individual, não podendo ser comparado com outra coisa qualquer.

[...]

Abstração é, portanto, uma forma de atividade mental que liberta o conteúdo ou dado, tido como essencial, de sua vinculação aos elementos irrelevantes, deles os distinguindo ou diferenciando (Jung, 1991, §§745-746, grifo nosso).

Definição apoiada por Jung na afirmativa de Kant: "Com efeito, quanto mais diferenças das coisas se

\footnotetext{
${ }^{13}$ Tratamos, aqui, da concepção atual de Lógica, cuja evolução implicou o desligamento das questões metafísicas de origem. Para Aristóteles, "cujo grupo de textos, reunidos no Organon, constitui o primeiro estudo amplo dessa disciplina" (Abbagnano, 2000, p. 624), é competência da Lógica o estudo do ser como verdadeiro; segundo mencionaram Reale e Antiseri, "é o tipo de ser próprio da mente humana que pensa as coisas e sabe conjugá-las como elas estão conjugadas na realidade ou separá-las quando elas estão separadas” (1990, p. 183).

${ }^{14}$ Por reconhecer isso, Jung $(1989, \S 22)$ afirmou que "a palavra é o símbolo da linguagem".

${ }^{15}$ Assim, Rita é bonita e Tupã é poderoso podem ser sinalizados no CQC com as seguintes notações: Br, Pt.
} 
apartarem de um conceito ou quanto mais se abstrair das várias determinações nele presentes, tanto mais abstracto é o conceito" (Kant, 2009, p. 94).

Trata-se, assim, na Lógica formalizada, de uma ação intelectual que, dobrando-se sobre si, extraiu $e$ isolou seu ciclo operatório do próprio contexto ideoafetivo. A formalização faz-se por esforço abstrativo do pensamento dirigido ao retroceder sobre suas operações. De onde mais poderia ela extrair a forma argumentativa senão do próprio pensar e mediante ele? Seria absurdo que a Lógica encontrasse seu objeto fora do pensar e, ainda mais, que não fosse essa mesma função mental a responsável pela a abstração retrocitada. No re-flectir-se da função pensamento, a Lógica encontrou sua gênese $\mathrm{e}^{16}$.

Tudo o que conhecemos (aquilo de que temos consciência) é primeiramente coisa psíquica (imagem ${ }^{17}$ ), pois a alma "é a única realidade imediata" e "é nesta realidade, a realidade do psíquico, que o psicólogo pode-se apoiar" (Jung, 1986c, §680). Mesmo as fórmulas matemáticas (tão formais quanto se queira) são "produtos da atividade puramente psíquica" (Jung, 1986a, §421). E se a "Psicologia pode lembrar, com toda a humildade, que o pensamento matemático é também uma função psíquica" (Jung, 1986a, §422); igualmente pode fazê-lo com o pensamento lógico.

Isso não significa psicologização da Lógica. Aprovamos a opinião segundo a qual a Lógica não faz parte da Psicologia. A Lógica não é psico-lógica; o que afirmamos é que ela não pode deixar de ser genética e imediatamente psíquica. Quanto ao pensamento dirigido e sua composição ideoafetiva, a Lógica, em seu formalismo característico, não se constitui $a b$ ovo, mas tão somente ex nunc, ou seja, de agora em diante, sem efeito retroativo, ela se acha retirada e separada daquele contexto psicológico. Considerar essa psicogênese da Lógica mostra-nos, entretanto, o circuito existente entre a diferenciação, como próprio da consciência, o pensamento dirigido e a abstração psicológica, ciclo que funda a redução do simbólico ao semiótico ao fixar cognições definidas - unívocas - sobre as produções do inconsciente.

\section{Pensamento dirigido e símbolos polissêmicos}

Se encontramos a psicologia da formalização lógica como suprassumo cultural da semiótica psíquica - cuja típica distinção dos opostos corresponde ao próprio da consciência; investigaremos, agora, a lógica do discurso psicológico sobre os símbolos. Qual o caminho da Psicologia Analítica para desenvolver suas análises e descrições da fenomenologia psíquica?

Vimos que os símbolos estabelecem uma polissemia por incluírem constitucionalmente o inconsciente em sua operação. 0 estudo psicológico captou tal polissemia nas construções do fantasiar e tomou ciência de suas qualidades confusas e paradoxais. Como função psíquica complexa, o símbolo fala às funções racionais e, simultaneamente, guarda-se resistente a elas. Ele "é sempre um produto de natureza altamente complexa, pois se compõe de dados de todas as funções psíquicas. Portanto, não é de natureza racional e nem irracional" (Jung, 1991, §912). Quando, por exemplo, o intelecto procura o significado de um símbolo produzido pela fantasia, depara-se com a situação lógica vexatória de vê-lo exigir "duas interpretações diametralmente

${ }^{16}$ A Psicologia Analítica conduz, assim, a compreensão assemelhada àquela da Epistemologia Genética, quando Jean Piaget afirmou: "se a lógica axiomatizada, ou como se diz, formalizada constitui efectivamente uma 'lógica sem sujeito', o problema do sujeito reaparece logo que perguntamos — e isso é necessário - de que a lógica constitui a axiomática. De facto, uma axiomática ou uma teoria formal é necessariamente o resultado da axiomatização ou da formalização de qualquer coisa, e perguntar-se de que é que a lógica representa a axiomatização conduz aos problemas de epistemologia derivada e, consequentemente, às relações da lógica com o sujeito, qualquer que seja a solução a que, a este respeito, formos conduzidos." (Piaget, 1980, p. 315). E, ainda: "acabaremos procurando mostrar que a lógica representa a axiomatização, não do pensamento natural nas suas manifestações conscientes, mas antes - o que não é a mesma coisa — das estruturas operatórias ou internas desse pensamento" (Piaget, 1980, p. 316).

17 'A palavra depreciativa 'psicologismo' atinge apenas os tolos que julgam ter a alma no bolso. [...] Tudo se passa como se as mencionadas pessoas não soubessem, ou então se esquecessem de que tudo aquilo que se torna consciente é imagem e de que imagem é alma" (Jung, 2002, §75).

Psicol. Argum. 2013 out./dez., 31(75), 717-727 
opostas" e que, "tanto uma, como outra, podem ser válidas" (Jung, 1988, §282), sob pena do sacrifício arbitrário de elementos inalienáveis do símbolo, caso se opte por um dos sentidos aferidos.

Mostramos noutro estudo como o "fenômeno inconsciente é refratário à circunscrição por uma sequência lógica simples"; que "ele talvez exija um paradoxo de sentido" (Vasconcelos, 1998, p. 105). Acatar isso significou um importante passo metodológico da Psicologia Analítica. Nós fornecemos, ali, uma crítica dos possíveis equívocos perpetrados por aqueles que, aferrados ao discurso unilateral ou levianamente situados na feitura paradoxal frouxa, não atingem a larga profundidade do estilo discursivo antitético em Psicologia Analítica. Gostaríamos de desenvolver aquela crítica, mediante a qual procuraremos enfrentar nossa atual questão.

Adotando o ponto de vista energético em Psicologia Analítica, Jung abandonou o substancialismo conceitual, captando a realidade no campo da funcionalidade (Vasconcelos, 1998, p. 110). Ele ratificou o consenso da matriz energética de pensamento segundo o qual todo fenômeno energético apresenta pares de opostos, ou seja, que "0 conceito de energia é inseparável da ideia de oposição" (Jung, 1991, §367):

Não se pode derivar o quente do frio nem o superior do inferior. Uma antítese ou é constituída de dois polos opostos ou não é antítese, e um ser é totalmente inconcebível sem uma polaridade, porque, de outro modo, seria impossível estabelecer sua existência (Jung, 1986, §414, grifos nossos ${ }^{18}$.
Compreendemos, assim, a afirmação junguiana de que "não há fenômeno que não seja energético" (Jung, 1991, §367).

0 estilo discursivo paradoxal realiza-se não por comodismo ou falta de rigor, mas para fazer jus à polaridade dos fenômenos. Jung, por causa disso, elogiou a forma antitética dos escritos gnósticos, os quais demonstravam mais preocupação com o incognoscível do que com uma apresentação clara do material, que roubaria do símbolo sua obscuridade constitucional, conduzindo o intelecto para o falso orgulho de supor explicado o fato transcendente. "O paradoxo, portanto, corresponde a um nível superior do intelecto e reproduz, com bastante fidelidade, o aspecto real da questão, transformando o incognoscível em cognoscível sem violência" (Jung, 1979, §417).

Essas considerações teóricas não conduziram Jung ao discurso psicológico frouxo. Considerou ele, em vez disso, que a compreensão simbólica não pode ocorrer, cientificamente, à revelia da lógica, mas como resultante da honesta confrontação lógica do intelecto com a polissemia simbólica:

Como a realidade não consiste de teorias nem as segue, os dois aspectos que somos forçados a pensar como divididos estão juntos num só, e tudo o que vive na alma reluz em múltiplas cores. [...] Quem acha que para um processo psíquico só pode haver uma única explicação verdadeira, esta vitalidade do conteúdo psíquico que necessita de duas teorias contraditórias é algo desesperador, principalmente se for um enamorado de verdades simples e, talvez, até incapaz de pensá-las juntas. (Jung, 1991, §927, grifo nosso).

\footnotetext{
${ }^{18}$ Eis aqui o coração da dialética junguiana. Definida não como dissolução dos contrários, mas sim como diálogo dos opostos, cuja unidade deve conceber-se como tensão coordenada. Para bem compreender nossa proposição, indicamos o estudo minucioso do importante parágrafo 61 do ensaio A Energia Psíquica; lá, C. G. Jung definiu: "A situação de represamento se caracteriza pela separação dos pares de opostos. Os pares de opostos permanecem unidos durante os processos psicológicos, enquanto dura a progressão da libido. [...] Um dos componentes do progresso, o qual resulta de um bem sucedido trabalho de adaptação, é que o impulso e seu contra-impulso, o positivo e o negativo, cheguem a uma interação e a uma influência mútua e recíproca regulares. Encontramos este equilíbrio e esta unificação dos opostos, por ex., no processo de reflexão diante de uma decisão difícil a tomar. No represamento da libido, onde se tornou impossível a progressão, o positivo e o negativo não podem mais se unir para um ato coordenado, porque tanto um como o outro atingiram o mesmo valor, mantendo-se equilibrados entre si” (Jung, 1990, §61). A coniunctio oppositorum não implica a resolução dos opostos envolvidos, mas o canal que lhes serve à coordenação recíproca e regular. Se um polo não deriva do outro, tampouco concebe Jung que se possam resolver. "Se a expressão inconsciente permanecer intacta, formará a matéria-prima não para um processo de resolução mas de construção, e ela se tornará o objeto comum da tese e da antítese”(200, 1991, §916).
} 
Diante da índole multicor e polimorfa da alma, a Psicologia Analítica se viu obrigada a aceitar como certas explicações opostas do mesmo evento psíquico e, consequentemente, a pensá-las unidas num paradoxo de sentido ou, energeticamente, numa unidade tensional coordenada. Naquilo que "somos forçados a pensar como divididos", encontramo-nos submissos, todavia, ao raciocínio de precisão, ou seja, válido logicamente, até alcançarmos o limite, a fronteira da circunscrição lógica do processo psíquico vivo.

A psicologia junguiana não se escusa da coerência do pensamento dirigido quando recorre ao paradoxo de sentido para expressar seus dados; enxerga nele a resultante de uma investigação intelectual responsável que, perante a polaridade psíquica, reconhece seu nec plus ultra. 0 paradoxo de sentido, portanto, consiste no evento dialético da conjunção simbólico-intelectiva para os opostos psíquicos. União que se reconhece, outrossim, carente ainda de uma conjunção simbólico-valorativa para o mesmo fato; pois o pensamento e o sentimento são igualmente requeridos na compreensão psicológica viva.

Tudo o que tentamos penetrar com o nosso intelecto acabará sempre em paradoxo e relatividade, quando se trata de trabalho honesto e não de petição de princípio que serve à comodidade. É certo que a compreensão intelectual do processo psíquico deve levar ao paradoxo e a relatividade, já porque o intelecto é apenas uma entre várias outras funções psíquicas que, por sua natureza, ajuda o homem a construir suas imagens dos objetos. Não pretendemos conhecer o mundo apenas com o intelecto; ele pode ser compreendido tão bem igualmente pelo sentimento. Por isso o julgamento do intelecto é, no máximo, a metade da verdade e deve, se for honesto, reconhecer sua insuficiência (Jung, 1991, §929).

A lógica na exposição psicológica sobre os símbolos apresenta-se da seguinte maneira: uma ferramenta utilíssima de viagem, mas não uma companheira de vida. Podemos compará-la com a reluzente corda élfica que Sam Gamgi ganhou, na saga $O$ Senhor dos Anéis, e da qual ele se lembra durante a descida dos escarpados das Emyn Muil, "cheio de excitação e alívio" (Tolkien, 2002, p. 287). A corda permitiu o resgate de Frodo e, também, a descida do perigoso penhasco, antes intransponível.

- Bem! - exclamou ele [Frodo]. - Conseguimos! Escapamos das Emyn Muil! E, agora, o que temos à frente, eu me pergunto? Talvez logo estejamos suspirando por uma boa rocha firme sob os pés outra vez.

Mas Sam não respondeu: estava olhando para trás, em direção ao penhasco. - Idiotas cabeças-duras! — disse ele. — Parvos! Minha bela corda! Ali está ela, amarrada a um tronco, e nós aqui no fundo. Uma ótima escadinha para aquele Gollum caviloso, a melhor que poderíamos ter deixado. Melhor colocar uma placa dizendo por onde fomos! Achei que tudo estava parecendo fácil demais (Tolkien, 2002, p. 290, grifo nosso).

Ao descerem a escarpa, a progressão vital e a marcha da missão exigiam deixar para trás a corda tão útil. Sam mostrou-se, entretanto, apegado à bela prenda élfica que acabara de lhes salvar e, pior, capaz de informar e ajudar seu perseguidor corrompido, o transtornado Gollum. Frodo, presente à vida apesar de toda a escuridão e desalento, age resoluto:

- Se você conseguir pensar em alguma forma pela qual pudéssemos ao mesmo tempo ter usado a corda e tê-la trazido conosco, então pode passar o título de idiota cabeça-dura para mim, ou qualquer outro nome que o velho Feitor lhe tenha dado - disse Frodo. - Suba lá, desamarre a corda e pule, se quiser! (Tolkien, 2002, p. 290).

Frodo indicou o momento oportuno do desapego ao instrumento: aquele no qual, de auxílio, a ferramenta transformou-se num estorvo de vida. Prender-se ao que funcionou bem, quando a vida exige avanço, sempre representou estagnação e perigo mortal. Tolkien "subcriou" ${ }^{19}$ em sua saga algo

${ }^{19}$ Quanto à ideia da arte (especialmente a arte fantástica) como subcriação, cf. Tolkien (2010). 
daquilo expresso, por exemplo, pelo Gênesis na fuga de Ló e sua família da cidade condenada de Sodoma. Ali, o anjo advertiu: "Salva-te, pela tua vida! Não olhes para trás de ti nem te detenhas em lugar nenhum da Planície" (Gn 19,17); porém, "a mulher de Ló olhou para trás e converteu-se numa estátua de sal" (Gn 19,26). Destino similar enfrentou o grande herói civilizador dos trácios, Orfeu, que, inconformado com a morte da ninfa Eurídice, sua amada, desceu ao Hades e provocou tal encantamento estético com sua voz e sua cítara que o mundo ctônio parou. Comovidos, os soberanos do inferno, Perséfone e Plutão, permitiram-lhe resgatar a esposa, mas lhe impuseram uma condição dificílima: "ele seguiria à frente e ela lhe acompanharia os passos, mas, enquanto caminhassem pelas trevas infernais, ouvisse o que ouvisse, pensasse o que pensasse, Orfeu não poderia olhar para trás, enquanto o casal não transpusesse os limites do império das sombras" (Brandão, 1988, p.142). Não suportando a dúvida, a carência, a incerteza e a impaciência de rever a esposa ausente, o cantor divino olhou para trás, em tempo apenas de ver Eurídice esvanecer numa sombra, morrendo novamente. "Olhar para trás" constitui o grande perigo que espreita na regressão psíquica: pode pôr a perder o desenvolvimento, petrificar, matar. Curiosamente, aquele que, na regressão, resiste à tentação do olhar para trás e desapega-se, retoma o progresso munido de novas e inesperadas perspectivas. É o caso de Sam, que, confrontado por Frodo com a estupidez de seu apego, recebe de volta a corda, como que por mágica. Também a Psicologia Analítica, ao assumir o nec plus ultra de uma lógica sobre o processo psíquico vivo, reencontra, paradoxalmente, a vida psíquica e suas leis. Todo conceito junguiano é, portanto, um conceito animado.

\section{Considerações finais}

Implicado na diferenciação consciente dos pares opostos, a produção de sinais integra-se com o pensamento dirigido e sua lógica. 0 próprio desenvolvimento da Lógica como disciplina de conhecimento associa-se intimamente à semiótica psíquica. Doutra forma, o fantasiar excede a produção unívoca, precisa e clara de significados na medida em que o símbolo não define ou determina um significado fixo, mas suscita significações múltiplas: verdadeira usina polissêmica da alma. A discriminação consciente, bem como a determinação conceitual pelo pensamento dirigido, constroem os signos mediante a redução dos significados provocados pelos símbolos. Isso conduz nossa experiência à segurança dos significados mais ou menos determinados e estáveis logicamente, o que constitui uma ferramenta utilíssima da cultura. A redução semiótica diante das instigações simbólicas de significado, entretanto, quando unilateralmente valorizada e fixada sem proporção, deságua na rigidez vital, na perda do viço significativo. Consequência inexorável tanto para a consciência individual quanto para a consciência coletiva.

Jung concordaria com seu contemporâneo, o mestre Zen-budista Dr. Daisetz Suzuki, para quem a razão de nós não alcançarmos uma completa compreensão da verdade deve-se à "nossa irracional aderência a uma interpretação lógica das coisas" (Suzuki, 1992, p. 81). A vida e, portanto, também a alma, transbordam de qualquer esquematismo lógico. Segundo concluiu o venerável mestre Zen: "nós, na realidade, vivemos psicologicamente e biologicamente - nunca logicamente" (Suzuki, 1992, p. 86).

O instrumentalismo da cultura contemporânea insiste há muito e sem equilíbrio no apego delusório à ferramenta, de tal modo que, muitas vezes, parecemos cegos a caminho do temerário e do desastroso. Em diversos setores da vida cotidiana, assomam os indícios de um tropismo irrefletido para a loucura de "subir, desamarrar a corda e pular de volta", com o fito de garantir a posse da ferramenta tão importante. Alguns, entretanto, pasmam aturdidos, porque são capazes de enxergar esses sintomas da consciência coletiva. E sua esperança se fia no numem do instinto de autoconservação, hábil, quiçá, em compensar o declive da ruína cultural. Qual retorno insidioso, justamente nestes indivíduos se realiza o concrescimento de uma atitude simbólica da consciência. Neles, talvez, possa brotar o equilíbrio distante capaz de coordenar o pensamento dirigido e a fantasia, a discriminação consciente e o tremendum caótico inconsciente; porque exatamente ali operam as condições psíquicas necessárias para transformá-los em instrumentos cooperativos de si mesmo na individuação. 


\section{Referências}

Abbagnano, N. (2000). Dicionário de filosofia (4. ed.). São Paulo: Martins Fontes.

Bíblia de Jerusalém. (2002). São Paulo: Paulus.

Brandão, J. S. (1989). Mitologia grega (Vol. 3). Petrópolis: Vozes.

Cascudo, C. (1954), Dicionário do folclore brasileiro. Rio de Janeiro: Ediouro.

Dalgalarrondo, P. (2008). Psicopatologia e semiologia dos transtornos mentais (2. ed.). Porto Alegre: Artmed.

Janet, P. (2006). Les nevroses. Chicoutimi: Bibliothèque PaulÉmile Boulet de l'Université du Québec. (Originalmente publicado em 1909, document produit en version numérique par Janick Gilbert, bénévole). Recuperado em 4 de abril, 2014, de http://classiques.uqac.ca/classiques/janet_pierre/nevroses/janet_les_nevroses.pdf

Jung, C. G.. (1950). Psychologische typen. Zürich: Rascher Verlag.

Jung, C. G. (1979). O símbolo da transformação na missa. Petrópolis: Vozes.

Jung, C. G. (1985). Mysterium coniunctionis: Pesquisas sobre a separação e a composição dos opostos psíquicos na alquimia. Petrópolis: Vozes.

Jung, C. G.. (1947-54/1986a). Considerações teóricas sobre a natureza do psíquico. In C. G. Jung. A natureza da psique (pp. 97-171). Petrópolis: Vozes.

Jung, C. G.. (1926/1986b). Espírito e vida. In C. G. Jung. A natureza da psique (pp. 259-279). Petrópolis: Vozes.

Jung, C. G.. (1931/1986c). O problema fundamental da psicologia contemporânea. In C. G. Jung. A natureza da psique (pp. 281-301). Petrópolis: Vozes.

Jung, C. G.. (1987). Relação da psicologia analítica com a obra de arte poética. In $O$ espírito na arte e na ciência (pp. 54-72). Petrópolis: Vozes.

Jung, C. G.. (1988). Interpretação psicológica do dogma da Trindade. Petrópolis: Vozes.

Jung, C. G.. (1989). Símbolos da transformação. Petrópolis: Vozes.
Jung, C. G. (1990). A energia psíquica. Petrópolis: Vozes. (Originalmente publicado em 1928).

Jung, C. G. (1991). Tipos psicológicos. Petrópolis: Vozes.

Jung, C. G.. (1997). Fundamentos de Psicologia Analítica (Tavistock Lectures). In C. G. Jung. A vida simbólica I (pp. 15-185). Petrópolis: Vozes.

Jung, C. G.. (1948/2000a). A fenomenologia do espírito no conto de fadas. In C. G. Jung. Os arquétipos e o inconsciente coletivo (pp. 203-266). Petrópolis: Vozes.

Jung, C. G.. (1954/2000b). Sobre os Arquétipos do Inconsciente Coletivo. In C. G. Jung. Os arquétipos e o inconsciente coletivo (pp. 13-49). Petrópolis: Vozes.

Jung, C. G. (2002). Comentário a "O segredo da flor de ouro". In C. G. Jung. Estudos alquímicos (pp. 13-59). Petrópolis: Vozes. (Originalmente publicado em 1957).

Jacobi, J. (1991). Complexo, arquétipo, símbolo na psicologia de C. G. Jung. São Paulo: Cultrix.

Kant, I. (2009). Lógica. Lisboa: Edições Texto \& Grafia.

Mortari, C. A. (2001). Introdução à Lógica. São Paulo: Editora Unesp.

Piaget, J. (1980). Epistemologia da Lógica. In J. Piaget. Lógica e conhecimento científico (pp. 315-334). Porto: Livraria Civilização Editora.

Pieri, P. F. (2002). Dicionário junguiano. São Paulo: Paulus.

Reale, G., \& Antiseri, D. (1990). História da Filosofia: Antiguidade e Idade Média (Vol. 1). São Paulo: Paulus.

Suzuki, D. T. (1992). Introdução ao Zen-budismo. São Paulo: Pensamento.

Tolkien, J. R. R. (2002). O senhor dos anéis: As duas torres. São Paulo: Martins Fontes.

Tolkien, J. R. R. (2010). Sobre histórias de fadas. São Paulo: Conrad Editora do Brasil.

Vasconcelos, J. W., Jr. (1998). 0 estado de identidade e o processo de projeção. Psicologia Argumento, 16(23), 103-124. 